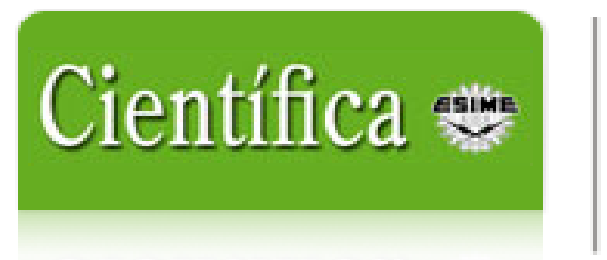

\title{
Científica
}

ISSN: 1665-0654

revista@maya.esimez.ipn.mx

Instituto Politécnico Nacional

México

Calva Chavarría, P. A.; del Moral, V. del; Cabrera, G. P.; de la Rosa, J.

New Proposal of Correction Factors for dc Voltages

Científica, vol. 9, núm. 3, 2005, pp. 119-123

Instituto Politécnico Nacional

Distrito Federal, México

Available in: http://www.redalyc.org/articulo.oa?id=61490303

How to cite

Complete issue

- More information about this article

Journal's homepage in redalyc.org

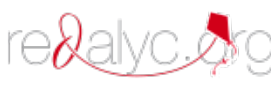

Scientific Information System Network of Scientific Journals from Latin America, the Caribbean, Spain and Portugal Non-profit academic project, developed under the open access initiative 


\section{New Proposal of Correction Factors for dc Voltages}

\section{P. A. Calva-Chavarría \\ V. del Moral \\ G. P. Cabrera \\ J. De la Rosa}

Laboratorios Pesados II,

Piso de Pruebas para Transformadores,

Escuela Superior de Ingeniería Mecánica y Eléctrica (ESIME), Instituto Politécnico Nacional (IPN).

Unidad Profesional "Adolfo López Mateos",

Col.Lindavista, México, DF.

MÉXICO.

email: primoalbertocch@hotmail.com

Recibido el 21 de junio de 2004; aceptado el 20 de enero de 2005.

\section{Abstract}

The IEC-60-1989 and IEEE Std. 4-1995 procedures for dc voltages are not suitable for high altitudes. The assumption that the streamer propagation field varies linearly with the relative air density does not apply to high-altitude dc breakdown. Recently it has been published some work related to the positive polarity, in this paper, finally, considering both positive and negative polarities a new proposal of correction factors for dc voltages is presented. It has been concluded that the effect of air density and humidity can be accounted for independently, that in positive polarity it is necessary to correct both for relative air density and for humidity, but in negative polarity only by relative air density, furthermore, a gap factor for different arrangements of electrodes is introduced.

\section{Resumen (Nueva propuesta de factores de corrección para tensiones de $\mathrm{cd}$ )}

Las normas internacionales IEC-60-1989 e IEEE Std. 4-1995 para tensiones de $\mathrm{cd}$ no son apropiadas para grandes altitudes. La suposición de que el campo de propagación de las flámulas o streamers varía linealmente con la densidad relativa del aire no aplica para rupturas eléctricas por tensiones de $\mathrm{cd}$ a grandes altitudes. Recientemente ha sido publicado traba relacionado con polaridad positiva, en este artículo, finalment considerando ambas polaridades positiva y negativa presenta una nueva propuesta de factores de corrección pa tensiones de cd. Se concluye que el efecto de la densida relativa del aire y de la humedad pueden ser tomados en cuen independientemente, que en polaridad positiva es necesar corregir por densidad relativa y por humedad, pero pa polaridad negativa solamente es necesario corregir $\mathrm{p}$ densidad relativa del aire, más aún, se introduce un factor c geometría para diferentes configuraciones de electrodos.

Keywords: Correction factors, dc high voltages, electric breakdown, IEC 60060-1, IEEE Std. 4-1995, high altitude

\section{Introduction}

For direct current $\mathrm{HV}$ atmospheric corrections at $\mathrm{HV}$ te laboratories the IEC-60-1989 and the IEEE Std.4-1995 a inappropriate. The correction methods are based on th identification of the predischarge regime as that of streamer In this way the measured breakdown field turns out to be th same as that required for propagation of streamers $E_{s}$, so th a voltage measurement $V$ at any atmospheric condition related to the standard condition measurement $V_{0}$ through th correction factor $K$.

$$
\begin{aligned}
& V=K V_{0} \\
& K=k_{1} k_{2}
\end{aligned}
$$

$k_{l}$ is the air density correction factor:

$$
k_{1}=\ddot{a}^{m}
$$

$k_{2}$ is the humidity correction factor:

$$
\begin{aligned}
& k_{2}=k^{w} \\
& k=1+0.014[\mathrm{~h} / \ddot{a}-11]
\end{aligned}
$$

Where $h$ is the absolute humidity in $\mathrm{g} / \mathrm{m}^{3} m$ and $w$ a coefficients that depend on the predischarge mode. Both and $w$ are function of the gradient factor defined as

$$
G=\frac{V}{500 d \delta k}
$$




\section{Científica}

Where $V / d$ is the measured gradient and $d$ the gap size. It is assumed that at sea level the streamer propagation field is 500 $\mathrm{kV} / \mathrm{m}$ and that at sea higher altitudes it varies linearly with $\delta$. Nevertheless, it has been demonstrated that this procedure is not suitable for high altitudes [1], because the streamer gradient does not varies linearly. On the base of positive conical-plane gaps experimental results, obtained at 2240 masl, it was proposed the following equations:

$$
\begin{aligned}
& E_{s}=500\left[\ddot{a}^{1.4}+1.3 \ddot{a}^{0.83}(h-11 / 100)\right] \\
& V=500 d\left(k_{1}+k_{2}\right) \\
& k_{1}=\ddot{a}^{1.4} \\
& k_{2}=1.3 \ddot{a}^{-0.83}(h-11 / 100)
\end{aligned}
$$

In this paper, considering experimental results for negative polarity and the previous results for positive polarity, a new correction factors for dc voltage is presented, additionally a gap factor for different electrode arrangements is introduced. New proposal of correction factors for dc voltages, it will allow better testing procedures and for that reasons better designs of equipment and electrical installations for dc voltages to be used at high altitude.

\section{Body}

\subsection{Experimental procedure}

A rode-plane configuration was used having three different types of rod electrodes, $0.02 \mathrm{~m}$ thick cylindrical rod with $36^{\circ}$ conical point, square cut rod $0.02 \times 0.02 \mathrm{~m}^{2}$ and hemispherical rod-plane, all were made of brass. The positive and negative HV dc was applied to the rod electrode, the plane electrode was connected to ground. During most of the test an average 0.77 value was recorded for the relative air density.

The tests were carried out in open air and fair weather in a high-altitude lab (elevation 2240 above sea level). For every gap separation a series of ten breakdowns were measured and then its mean value calculated.

\subsection{Experimental results and analysis}

\section{Positive polarity}

Considering $h=11 \mathrm{~g} / \mathrm{m}^{3}$ figure 1 shows the electric field calculated with equation (7) obtained for conical rod-plane gaps, and experimental results for square cut rod-plane and for hemispherical rod-plane gaps.

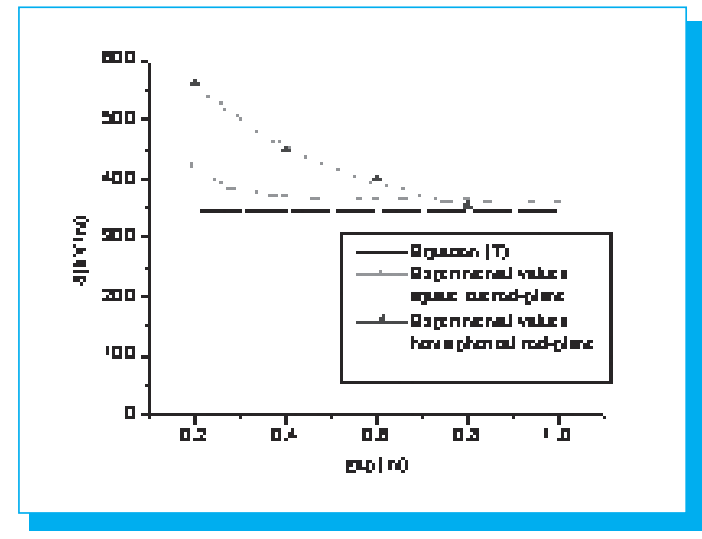

Fig. 1. Streamer propagation field, $h=11 \mathrm{~g} / \mathrm{m} 3,2240$ masl.

The streamer propagation field for experimental values vari depending of the gap size; this suggest that the equation (" can be written as:

$$
E_{s}=500\left[k_{1}+k_{2}\right] S
$$

where $S$ is defined as a gap factor.

From the curve fitting result for conical rod-plane $S=1$, squa cut rod-plane $S=1.01 d^{-0.10}$ and for hemispherical ended ro plane $S=0.965 d^{-0.33}$. Figure 2 shows the breakdown voltag as function of the gap distances.

It is well known that at sea level the differences between th breakdown voltages are minimum for gap distances $>0.5 \mathrm{n}$ nevertheless for 2240 masl this occurs practically $\mathrm{fc}$ distances $>0.8 \mathrm{~m}$.

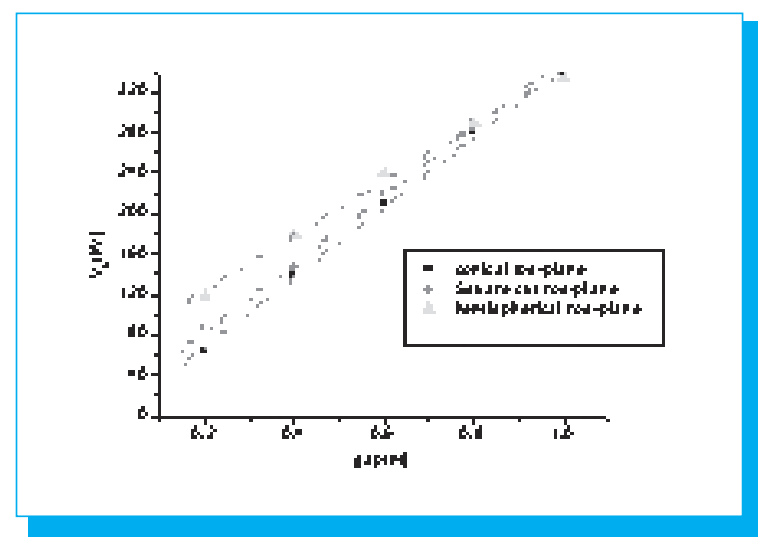

Fig. 2. Breakdown voltages as function of the gap size, 2240 masl. 


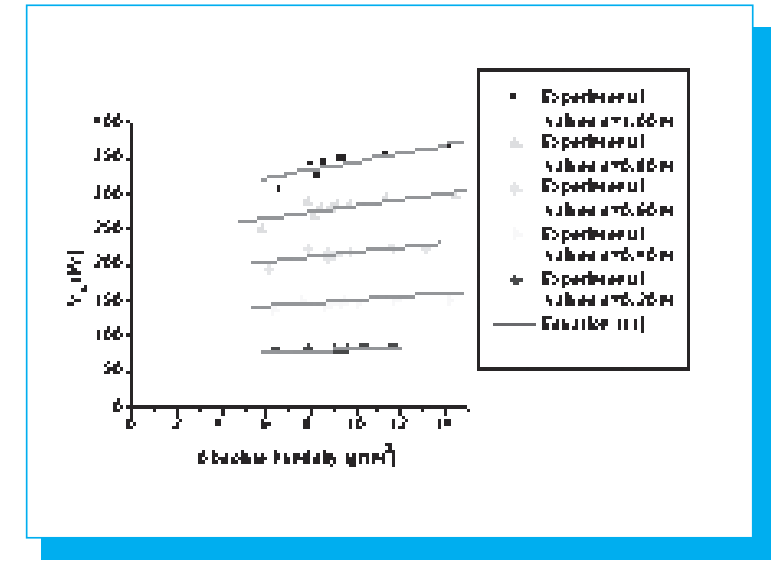

Fig. 3. Breakdown voltage as function of humidity. Lines represent the calculated values.

Figures 3 and 4 show for square cut rod-plane and the hemispherical rod-plane the experimental breakdown values and those calculated with the new proposal for positive polarity.

\section{Negative polarity}

The negative streamer propagation for conical rod-plane and $h=11 \mathrm{~g} / \mathrm{m}^{3}$ is given by $\mathrm{E}_{\mathrm{so}}=1476.4-1121.91 d[4]$ :

For an altitude of 2240 masl for the same conical rod-plane and $h=11 \mathrm{~g} / \mathrm{m}^{3}$, it was obtained the experimental results showed in table 1 .

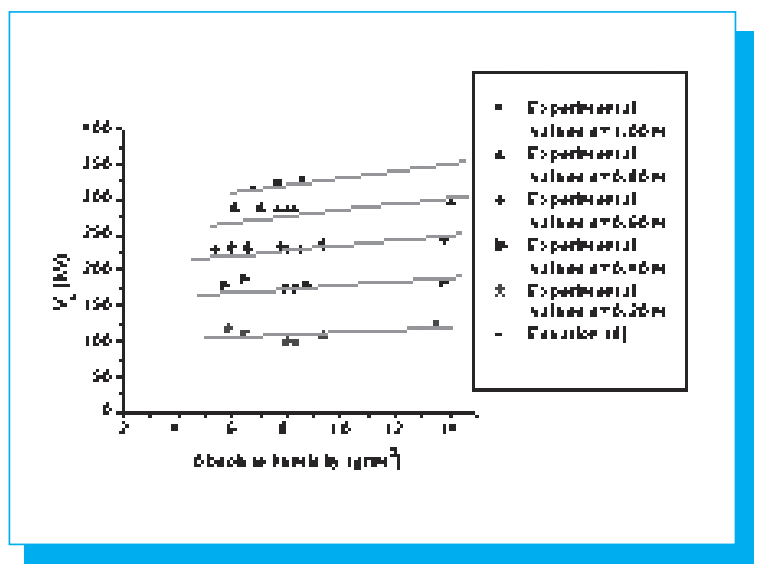

Fig. 4. Breakdown voltage as function of humidity. Lines represent the calculated values.
Tabla 1. Negative streamer propagation field for the different arrangements of electrode, $h=11 \mathrm{~g} / \mathrm{m} 3,2240$ masl.

\begin{tabular}{|c|c}
\hline \hline Gap (m) & $\boldsymbol{E}_{\text {s11 }}(\mathbf{k V} / \mathbf{m})$ \\
\hline 0.09 & 1245.02 \\
\hline 0.12 & 1155.46 \\
\hline 0.15 & 1171.93 \\
\hline 0.18 & 1141.03 \\
\hline 0.21 & 1144.95 \\
\hline 0.24 & 1053.89 \\
\hline 0.27 & 1019.23 \\
\hline 0.30 & 1005.06 \\
\hline 0.33 & 984.48 \\
\hline 0.36 & 972.26 \\
\hline
\end{tabular}

It is possible to observe that the negative streamer propagatic field decreases if the gap distances are increased, this is agreement with [3]. For the air density correction equatic (11) is written as:

$$
E_{s}=E_{s o} k_{1} S
$$

With $k_{l}=\ddot{a}^{0.446}$ for conical rod-plane gaps.

Figure 5 shows the negative streamer electric field for conic rod-plane versus gap distance obtained experimentally an with equation (12). At the same time experimental values square cut rod-plane and hemispherical rod-plane are plotte

At sea level it has been observed that for negative point-plar arrangements the predischarge is by streamer for interelectroc

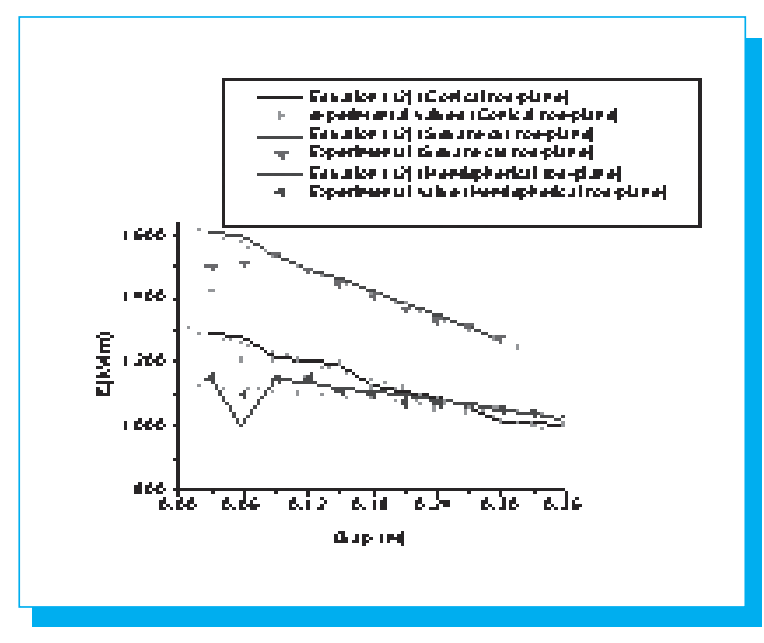

Fig. 5. Negative propagation streamer field, 2240 masl. 


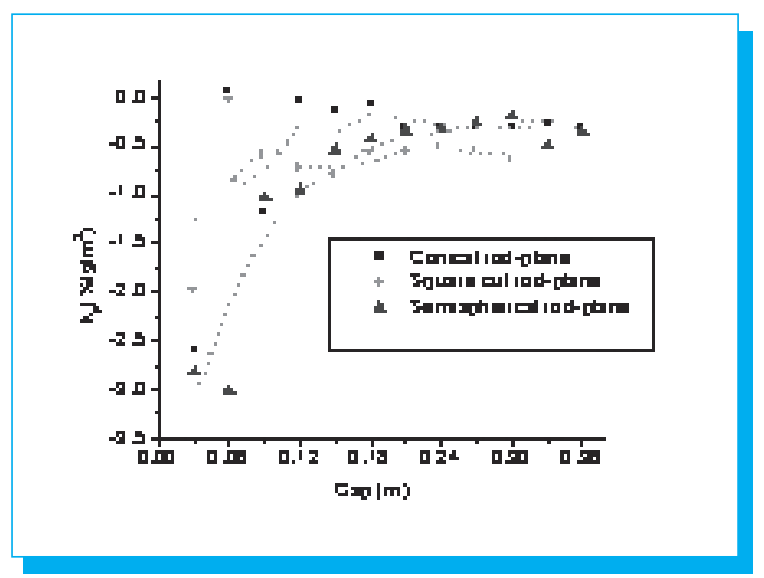

Fig. 6. Coefficient of absolute humidity kh versus gap size for the different configurations of electrodes.

distances $>0.1 \mathrm{~m}$; at 2240 masl the predischarge by streamers it was for distances $>0.09 \mathrm{~m}$; this explains the strong deviation of the experimental results for small gap distances.

It can see that in all cases the propagation of the negative streamer is function of the gap. Nevertheless as the conical rod-plane is taken as the reference configuration, its curve fitting includes intrinsically the dependence of the gap, so that it is considered $S=1$, for square cut rod-plane $S=1.25$ and for hemispherical rod-plane $S=0.49 d+0.88$.

For calculating the effect of the absolute humidity on the breakdown voltage we use the coefficient of humidity defined as [4]:

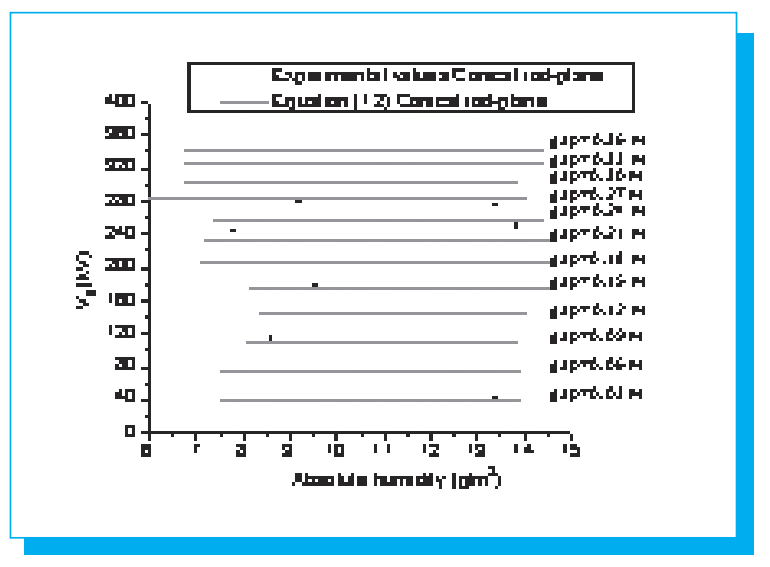

Fig. 7. Breakdown voltage as function of absolute humidity for conical rod-plane configuration.

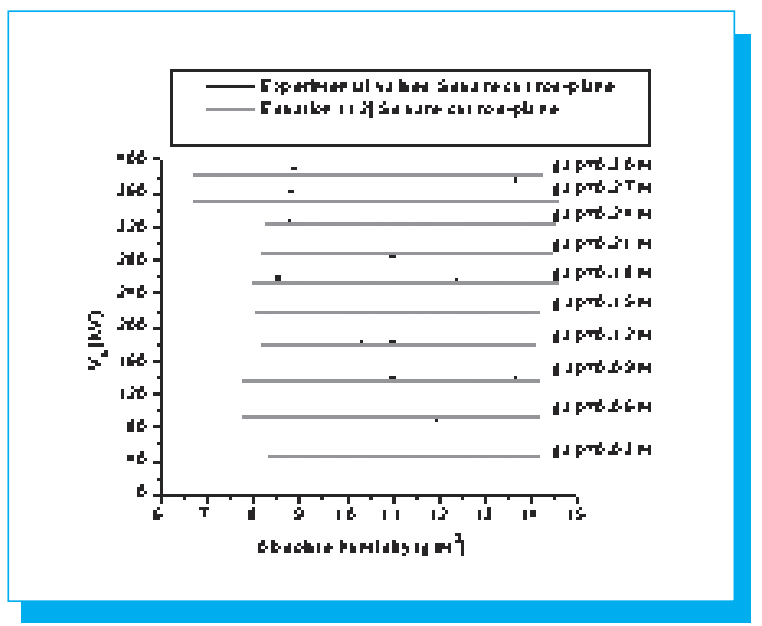

Fig. 8. Breakdown voltage as function of absolute humidity for square cut rod-plane configuration.

$$
\frac{K_{h}}{100}=\left(\frac{E_{s}-E_{s o}}{E_{s o}}\right)\left(\frac{1}{h-h_{o}}\right)
$$

Figure 6 shows the coefficient of the absolute humidity $k_{h}$ $\left(\% / \mathrm{g} / \mathrm{m}^{3}\right)$ for the different configurations of electrodes.

Figure 7, 8 and 9 show the breakdown voltage as function of the absolute humidity.

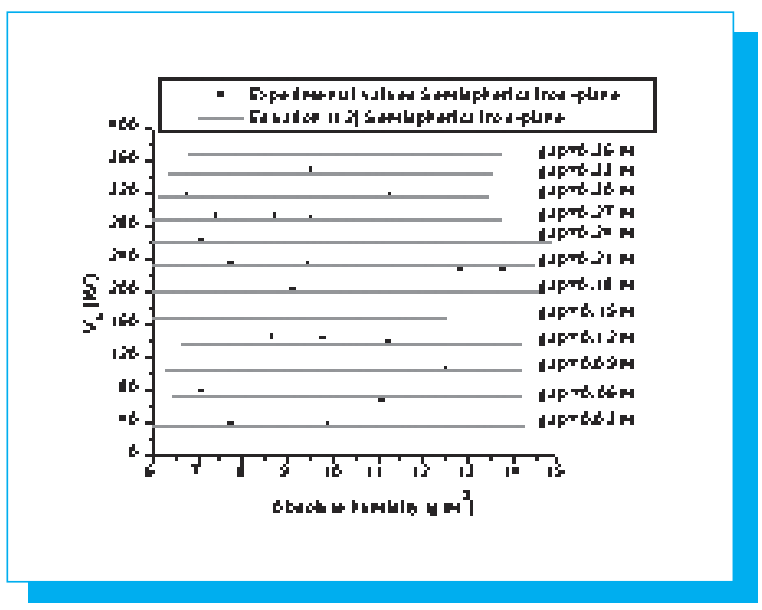

Fig. 9. Breakdown voltage as function of absolute humidity for hemispherical rod-plane configuration. 


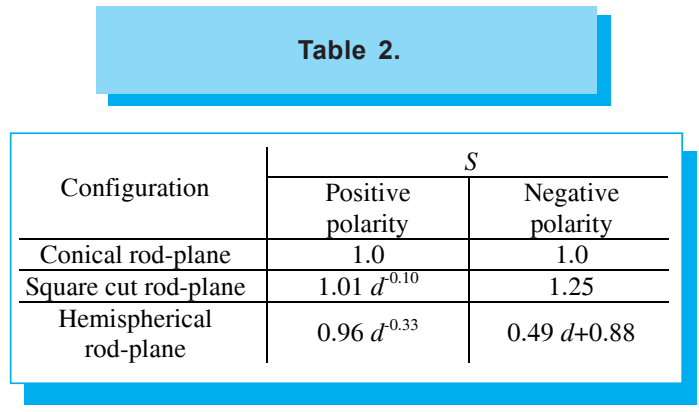

It can be noted that there is no influence of the humidity on the negative breakdown voltages for all the electrodes configurations tested.

\section{Conclusions}

The conclusion is the following practical procedure for HV laboratories at high altitudes:

«Any breakdown voltage $V_{b}$ it is related to the standard conditions trough out the following equation.

$$
V_{b}=E_{s o} d\left[k_{1}+k_{2}\right] S
$$

where

$V_{b}=$ Breakdown voltage in $\mathrm{kV}$ at any atmospheric condition.

$E_{s o}=$ Streamer propagation electric field at standard reference atmosphere $\left(h=11 \mathrm{~g} / \mathrm{m}^{3}, \ddot{a}=1\right)$. For positive polarity it assumed as $500 \mathrm{kV} / \mathrm{m}$ and negative polarity is $E_{s o}=1476.4$ $1121.91 d$

$d=$ gap size in $\mathrm{m}$

$k_{l}=$ air density correction factor defined as: $k_{l}=\ddot{a}^{m}$

$m=1.4$ for positive polarity

$m=0.44$ for negative polarity $\ddot{a}=$ relative air density

$$
\delta=\frac{b}{b_{o}} \quad \frac{273+t_{o}}{273+t}
$$

$b=$ atmospheric pressure $(\mathrm{kPa})$

$b_{\mathrm{o}}=$ standard atmospheric pressure $(101.3 \mathrm{kPa})$

$t=$ ambient temperature $\left({ }^{\circ} \mathrm{C}\right)$

$t_{o}=$ standard ambient temperature $\left(20^{\circ} \mathrm{C}\right)$

$k_{2}=$ humidity correction factor

for positive polarity

$$
k_{2}=1.3 \delta^{-0.83} \frac{h-11}{100}
$$

for negative polarity $k_{2}=0$

$S=$ gap factor that depends of the geometry of the rod electroc and the polarity». (Table 2)

\section{References}

[1] P.A. Calva and F.P. Espino, «Correction Factors f Positive dc Voltages,» IEEE Transactions on Dielectri and Electrical Insulation, Vol. 5, No. 4, August 1998.

[2] Allen N. L., Boutlendj M. and Lightfoot H.A., «Dielectr Breakdown in No uniform Field Air Gaps», IEE Transactions on Electrical Insulation, vol. 28 No. 2, p 183-190, April 1993.

[3] Robledo-Martínez A. and Calva P.A., «DC Breakdown Rod-rod and Rod-Plane Gaps in Reduced-Density Ai $6^{\text {th }}$ International Symposium on High Voltage Engineerin New Orleans, LA, USA, 1989, paper 46.02.

[4] Allen N.L. and Boutlendj M., «Study of the Electric Fiel Required for Streamer Propagation in Humid Air», IE Proceedings-A, vol. 138, No. 1, pp 37-43, January 1991

\section{$4^{\circ}$ Congreso Internacional de INGENIERÍA ELECTROMECÁNICA Y DE SISTEMAS}

